\title{
Real-Manufacturing-Process Finite Element Modeling of Aramid Honeycomb for Cutting Mechanism Revealing
}

\author{
Yuxing Yang \\ Dalian Maritime University \\ Yongjie Bao ( $\sim$ yongjie@dlmu.edu.cn ) \\ Dalian Maritime University \\ Qihao Xu \\ Dalian University of Technology \\ Jinlong Wang \\ Dalian Maritime University
}

Original Article

Keywords: Aramid honeycomb, Finite element modeling, Cutting process, Cutting damages

Posted Date: February 11th, 2021

DOI: https://doi.org/10.21203/rs.3.rs-182370/v1

License: (c) (i) This work is licensed under a Creative Commons Attribution 4.0 International License. Read Full License 


\title{
Real-manufacturing-process finite element modeling of aramid honeycomb for cutting mechanism revealing
}

\author{
Yuxing Yang ${ }^{1, *}$, Yongjie Bao ${ }^{1, *}$, Qihao $\mathrm{Xu}^{2}$, Jinlong Wang ${ }^{1}$ \\ ${ }^{1}$ Marine Engineering College, Dalian Maritime University, Dalian 116026, China; \\ ${ }^{2}$ School of Mechanical Engineering, Dalian University of Technology, Dalian 116024, China.
}

\begin{abstract}
A finite element model for honeycomb cutting was proposed to reveal its cutting mechanism in the process of cutting with disc cutter, which solves the problem of efficient honeycomb cutting modeling by imitating the real manufacturing process of the aramid honeycomb and solves the problem of honeycomb material assignment by developing a material calculation method. Cutting experiment of ACCH-1-1.8348 aramid honeycomb specimen concerning on the cutting forces response and cutting damages was conducted. The comparison between the finite element model results and the experimental results validated that the proposed method was effective for investigating the cutting process and mechanism for the aramid honeycomb. Predicted cutting mechanism results show that: (a) cutting process of the aramid honeycomb can be divided into 3 stages with 4 characteristic states: initial state, cut-in state, cut-out state and final state; (b) cell wall bending in the cutting direction relieves the cutting force, and strong plasticity of the aramid fiber makes it hard to break, which lead to uncut fiber and burr damages; (c) using sharp tip cutter as well as bonding both top and bottom of the honeycomb to two stiffer parts individually are beneficial to obtain good cutting quality with less damages.
\end{abstract}

Key words: Aramid honeycomb; Finite element modeling; Cutting process; Cutting damages

\section{Introduction}

Aramid honeycomb, such as Nomex ${ }^{\circledR}$, whose mechanical properties show orthotropic anisotropy due to the unique close-packed hexagonal structure $\left[{ }^{1}\right]$, is a porous material made of aramid fiber and phenolic

*Corresponding author:

E-mail: yongjie@dlmu.edu.cn (Yongjie Bao) yangyuxing@dlmu.edu.cn (Yuxing Yang) 
$\operatorname{resin}^{[2]}$. It exhibits good performance, such as high specific strength, excellent flame retardancy, good corrosion resistance and shock absorption $\left[{ }^{3}\right]$, which makes it a promising core material for lightweight collision energy absorption structures in aerospace engineering (such as fairing, flap and hatch door) and marine engineering (such as hull of racing boat and fireproof bulkhead) $\left[{ }^{4}-\right]$.

The aramid honeycomb is usually manufactured by the stretching expansion process, during which shape of the aramid paper is fixed by glue $\left[{ }^{9}{ }^{10}\right]$. After stabilizing, honeycomb core is dipped in the phenolic resin. Finally, it can be cut into plate with desired size $\left[{ }^{11}\right]$. Generally, the cutting process will lead to inevitable defects $\left[{ }^{12}\right]$, such as tear, burr and uncut fiber. Observable cutting defects in the experiment are limited and most of them are the final results. In order to reveal the cutting mechanism during the cutting process, it is necessary to establish numerical model of honeycomb cutting, which can help understand evolution of the cutting defects.

A good numerical model of honeycomb cutting, which has a good match with the experimental results, can visually reveal the cutting deformation and damage mechanism of the honeycomb with lower costs than experiments. A lot of numerical methods for honeycomb modeling have been developed, which can be mainly divided into 2 types, homogenized model and detailed model. The homogenized model, including isotropic homogenized model and orthotropic homogenized model, neglects the multi-layer nature. The isotropic homogenized model neglects orthotropic material behavior of the honeycomb material, while the orthotropic homogenized model considers it. The detailed model considers the multilayer nature of the honeycomb material, which models the aramid paper and phenolic resin individually. Four modeling approaches of Nomex honeycomb were benchmarked in literature $\left[{ }^{13}\right]$, including singlelayer isotropic approach (isotropic homogenized model), single-layer orthotropic approach (orthotropic homogenized model), multi-layer resin coating approach (detailed model based on planar laminate theory) and multi-layer resin corner approach (detailed model considering resin accumulation in the hexagon corners); the most recommended approach was the single-layer orthotropic approach (orthotropic 
homogenized model) since it enabled simultaneous calibration for all four loading conditions and had a good agreement with the test results. In addition, an analytical homogenized model of composite cell wall honeycomb was also developed by Wang $\left[{ }^{14}\right]$ for computing costs reducing by modeling the locally heterogeneous honeycomb as a homogeneous orthotropic bulk, whose stiffness matrix was derived by combining Gibson and Ashby's model $\left[{ }^{15}\right]$ and the classic laminated beam theory model.

In this paper, to reveal the cutting mechanism in the process of aramid honeycomb cutting, a realmanufacturing-process finite element model (FEM) based on 3D Hashin criteria is proposed. The honeycomb cutting model is established by imitating the real manufacturing process, and a material calculating method for aramid honeycomb is developed, which considers both mechanical properties of the core material and that of the resin. A validation experiment is conducted, whose cutting force response and damages are compared with that from the finite element model. Finally, the cutting mechanism during cutting the aramid honeycomb is revealed using the proposed FEM.

\section{Real-manufacturing-process finite element model}

\subsection{Efficient model of honeycomb cutting}

In order to have a knowledge of the cutting mechanism, finite element analysis was of the aramid honeycomb cutting was conducted. The FEM of the honeycomb and its cutting was shown in Fig.1. The $\mathrm{X}$-axis in Fig. 1 is along the direction of ribbon length $\mathrm{L}$, the Y-axis is along the out-of-plane direction $\mathrm{W}$, and the $\mathrm{Z}$-axis is along the direction of expansion $\mathrm{H}$. The aramid honeycomb was modeled by imitating the real manufacturing process. First of all, an aramid ribbon with fixed shape was modeled and assigned with material considering both core material and resin. Then the ribbon was tied (simulating interface bonding effect) with another one to form the first layer honeycomb structure. As more and more ribbons were tied together, the aramid honeycomb model would be finally formed. The geometry of the aramid honeycomb was illustrated in Fig.1, in which L, W and $\mathrm{H}$ are length, width and height of the specimen, $h$ is cutting depth, $a$ is double wall length, $b$ is single wall length, $t$ is single wall thickness and $\varphi$ is corner 
angle. A part of the sharp disc cutter was modeled as a 3D discrete rigid and constrained to the reference point RP as rigid body. The cutter tip was treated as a very small radius arc to improve the contact effect between the cutter and honeycomb in the cutting process.

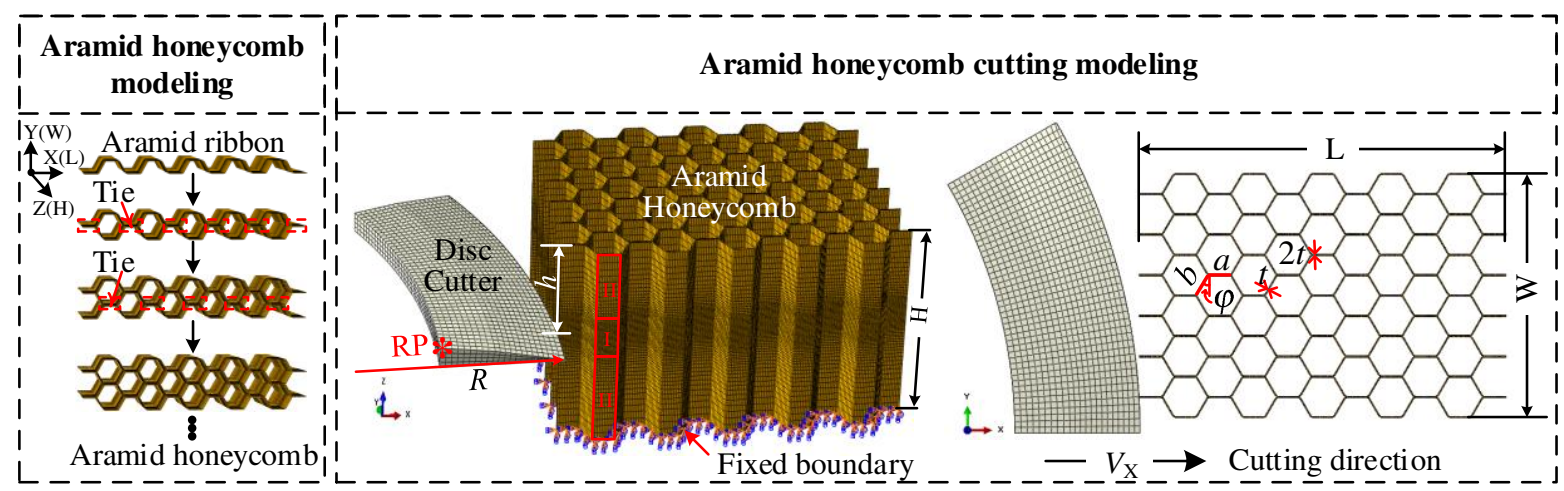

Fig.1 Finite element modeling of the aramid honeycomb cutting process.

C3D8R element (3D 8-node reduced integral element in Abaqus) with 'stiffness' hourglass control method was used for the workpiece. After mesh dependence studying with considering the computational cost and results accuracy, mesh size within the area I was set as $0.1 \mathrm{~mm}$, while that within the area II changes from $0.5 \mathrm{~mm}$ to $0.1 \mathrm{~mm}$ by using single direction bias. The global mesh size of the cutter was 0.5 $\mathrm{mm}$, while mesh was refined at the cutter tip with the smallest element size of $0.01 \mathrm{~mm}$.

Constant velocity $V_{\mathrm{x}}$ along the direction of ribbon length was loaded on the reference point RP of the cutter. Displacement $U_{\mathrm{x}}$, reaction forces $R F_{\mathrm{x}}$ and $R F_{\mathrm{y}}$ of the reference point were recorded during the cutting process. General contact with 'hard contact' normal behavior and penalty friction tangential behavior (friction coefficient was 0.3 ) was established between the cutter and the workpiece.

\subsection{Material properties}

Generally, mechanical properties of the aramid honeycomb are determined by the core material (e.g. Nomex paper) and the resin (e.g. Phenolic resin) considering its manufacturing process. First, mechanical properties of the core material and the resin can be obtained from the manufacturer and/or research papers. Then mechanical properties of the impregnated aramid honeycomb paper can be calculated based on the superposition principle, as shown in Eqs. (1) (8). The symbols with superscript 'co' and 're' represent the 
mechanical property of the core material and mechanical property of the resin, respectively, while that without superscript represents the mechanical property of the impregnated aramid honeycomb paper. The symbol with subscript ' $\mathrm{T}$ ' represents the tensile property, while that with subscript ' $\mathrm{C}$ ' represents the compressive property. The subscript 'L' means the direction of ribbon length (longitudinal direction), while subscript ' $\mathrm{H}$ ' means the direction of expansion (transverse direction).

Elastic modulus along the direction of ribbon length $E_{\mathrm{L}}$ and that along the direction of expansion $E_{\mathrm{H}}$ of the impregnated aramid honeycomb paper can be expressed as follows:

$$
\begin{aligned}
& E_{\mathrm{L}}=E_{\mathrm{L}}^{\mathrm{co}}\left(1-V^{\mathrm{re}}\right)+E_{\mathrm{L}}^{\mathrm{re}} V^{\mathrm{re}} \\
& E_{\mathrm{H}}=E_{\mathrm{H}}^{\mathrm{co}}\left(1-V^{\mathrm{re}}\right)+E_{\mathrm{H}}^{\mathrm{re}} V^{\mathrm{re}}
\end{aligned}
$$

where $V^{\text {re }}$ (volume of the resin) represents the resin content, which is related with the density of the aramid honeycomb, as given in Table 1.

Table 1 The resin content for different density honeycomb $\left[{ }^{16}\right]$.

\begin{tabular}{cccccc}
\hline Honeycomb density $\left(\mathrm{kg} / \mathrm{m}^{3}\right)$ & 48 & 64 & 80 & 96 & 123 \\
\hline Resin content $(\%)$ & 34.1 & 50.6 & 60.4 & 67.0 & 74.3 \\
\hline
\end{tabular}

In-plane Poisson's ratio $v_{\text {in }}$ and out-of-plane Poisson's ratio $v_{\text {out }}$ of the impregnated aramid honeycomb paper can be obtained by Eq. (3) and Eq. (4).

$$
\begin{aligned}
& v_{\text {in }}=v_{\text {in }}^{\mathrm{co}}\left(1-V^{\mathrm{re}}\right)+v^{\mathrm{re}} V^{\mathrm{re}} \\
& v_{\text {out }}=\frac{v_{\text {in }}\left(E_{\mathrm{L}}-v_{\text {in }} E_{\mathrm{W}}\right)}{E_{\mathrm{L}}\left(1-v_{\text {in }}\right)}
\end{aligned}
$$

In-plane shear modulus $G_{\text {in }}$ and out-of-plane shear modulus $G_{\text {out }}$ of the impregnated aramid honeycomb paper can be obtained by Eq. (6).

$$
\begin{gathered}
G_{\text {in }}=\frac{\mathrm{E}_{\mathrm{L}}}{2\left(1+v_{\text {in }}\right)} \\
G_{\text {out }}=\frac{\mathrm{E}_{\mathrm{H}}}{2\left(1+v_{\text {out }}\right)}
\end{gathered}
$$

Density of the impregnated aramid honeycomb paper $\rho$ can be obtained by Eq. (7). 


$$
\rho=\rho^{\mathrm{co}}\left(1-V^{\mathrm{re}}\right)+\rho^{\mathrm{re}} V^{\mathrm{re}}
$$

Tensile strength along the direction of ribbon length $S_{\mathrm{LT}}$ and that along the direction of expansion $S_{\mathrm{HT}}$, compressive strength $S_{\mathrm{LC}}$ and $S_{\mathrm{HC}}$, shear strength $S_{\mathrm{LS}}$ and $S_{\mathrm{HS}}$, can be calculated by Eq. (8).

$$
S_{i j}=S_{i j}^{\mathrm{co}}\left(1-V^{\mathrm{re}}\right)+S_{i j}^{\mathrm{re}} V^{\mathrm{re}}(i=\mathrm{L}, \mathrm{H} ; j=\mathrm{T}, \mathrm{C}, \mathrm{S})
$$

\subsection{Damages prediction}

3D Hashin criteria can be used to predict the damage initiation of the honeycomb $\left[{ }^{17}\right]$, which concludes fiber tensile failure and compressive failure, matrix cracking and crushing, delamination in tension and in compression, and fiber-matrix shear-out, as shown in Eqs. (9) (15), where $\sigma_{i}(i=1,2,3)$ are normal stresses, $\tau_{i j}(i, j=1,2,3 ; i \neq j)$ are shear stresses.

Fiber tensile failure (FT), for $\left(\sigma_{1}>0\right)$ :

$$
\left(\frac{\sigma_{1}}{S_{\mathrm{LT}}}\right)^{2}+\left(\frac{\tau_{12}}{S_{\mathrm{LS}}}\right)^{2}+\left(\frac{\tau_{13}}{S_{\mathrm{LS}}}\right)^{2}=e_{\mathrm{FT}}^{2}
$$

Fiber compressive failure (FC), for $\left(\sigma_{1}<0\right)$ :

$$
\left(\frac{\sigma_{1}}{S_{\mathrm{LC}}}\right)^{2}=e_{\mathrm{FC}}^{2}
$$

Matrix cracking (MT), for $\left(\sigma_{2}>0\right)$ :

$$
\left(\frac{\sigma_{2}}{S_{\mathrm{HT}}}\right)^{2}+\left(\frac{\tau_{12}}{S_{\mathrm{LS}}}\right)^{2}+\left(\frac{\tau_{23}}{S_{\mathrm{HS}}}\right)^{2}=e_{\mathrm{MT}}^{2}
$$

Matrix crushing $(\mathrm{MC})$, for $\left(\sigma_{2}<0\right)$ :

$$
\left(\frac{\sigma_{2}}{S_{\mathrm{HC}}}\right)^{2}+\left(\frac{\tau_{12}}{S_{\mathrm{LS}}}\right)^{2}+\left(\frac{\tau_{23}}{S_{\mathrm{HS}}}\right)^{2}=e_{\mathrm{MC}}^{2}
$$

Delamination in tension (DT), for $\left(\sigma_{3}>0\right)$ : 


$$
\left(\frac{\sigma_{3}}{S_{\mathrm{HT}}}\right)^{2}+\left(\frac{\tau_{13}}{S_{\mathrm{LS}}}\right)^{2}+\left(\frac{\tau_{23}}{S_{\mathrm{HS}}}\right)^{2}=e_{\mathrm{DT}}^{2}
$$

Delamination in compression (DC), for $\left(\sigma_{3}<0\right)$ :

$$
\left(\frac{\sigma_{3}}{S_{\mathrm{HC}}}\right)^{2}+\left(\frac{\tau_{13}}{S_{\mathrm{LS}}}\right)^{2}+\left(\frac{\tau_{23}}{S_{\mathrm{HS}}}\right)^{2}=e_{\mathrm{DC}}^{2}
$$

Fiber-matrix shear-out (FMS), for $\left(\sigma_{1}<0\right)$ :

$$
\left(\frac{\sigma_{1}}{S_{\mathrm{LC}}}\right)^{2}+\left(\frac{\tau_{12}}{S_{\mathrm{LS}}}\right)^{2}+\left(\frac{\tau_{13}}{S_{\mathrm{LS}}}\right)^{2}=e_{\mathrm{FMS}}^{2}
$$

when one of the above equations satisfies that $e_{k} \geqslant 1$ ( $\left.k=\mathrm{FT}, \mathrm{FC}, \mathrm{MT}, \mathrm{MC}, \mathrm{DT}, \mathrm{DC}, \mathrm{FMS}\right)$, the damage variable $d_{k}$ will be set to 1 , which represents that the element has been damaged. Then effective stiffness matrix $C^{\mathrm{d}}$ associated with stiffness degradation after damage initiation point can be expressed by Eqs. (16) (17). The subscript FF, MF and DF represent fiber failure (tensile or compressive), in-plane matrix failure (cracking or crushing) and delamination (in tension or compression), respectively, which depend on the specific strain status.

$$
\begin{aligned}
& \mathbf{C}^{\mathrm{d}}=\left[\begin{array}{cccccc}
C_{11}^{\mathrm{d}} & C_{12}^{\mathrm{d}} & C_{13}^{\mathrm{d}} & 0 & 0 & 0 \\
& C_{22}^{\mathrm{d}} & C_{23}^{\mathrm{d}} & 0 & 0 & 0 \\
& & C_{33}^{\mathrm{d}} & 0 & 0 & 0 \\
& \text { symmetric } & & C_{44}^{\mathrm{d}} & 0 & 0 \\
& & & C_{55}^{\mathrm{d}} & 0 \\
& & & C_{66}^{\mathrm{d}}
\end{array}\right] \\
& C_{11}^{\mathrm{d}}=\left(1-d_{\mathrm{FF}}\right) C_{11}, C_{22}^{\mathrm{d}}=\left(1-d_{\mathrm{FF}}\right)\left(1-d_{\mathrm{MF}}\right) C_{22}, C_{33}^{\mathrm{d}}=\left(1-d_{\mathrm{FF}}\right)\left(1-d_{\mathrm{DF}}\right) C_{33}, \\
& C_{12}^{\mathrm{d}}=\left(1-d_{\mathrm{FF}}\right)\left(1-d_{\mathrm{MF}}\right) C_{12}, C_{13}^{\mathrm{d}}=\left(1-d_{\mathrm{FF}}\right)\left(1-d_{\mathrm{DF}}\right) C_{13}, C_{23}^{\mathrm{d}}=\left(1-d_{\mathrm{MF}}\right)\left(1-d_{\mathrm{DF}}\right) C_{23}, \\
& C_{44}^{\mathrm{d}}=\left(1-d_{\mathrm{FMS}}\right)^{2} C_{44}, C_{55}^{\mathrm{d}}=\left(1-d_{\mathrm{FF}}\right)\left(1-0.9 d_{\mathrm{DT}}\right)\left(1-0.5 d_{\mathrm{DC}}\right) C_{55}, \\
& C_{66}^{\mathrm{d}}=\left(1-0.9 d_{\mathrm{MT}}\right)\left(1-0.5 d_{\mathrm{MC}}\right)\left(1-0.9 d_{\mathrm{DT}}\right)\left(1-0.5 d_{\mathrm{DC}}\right) C_{66}
\end{aligned}
$$

\section{Validation experiment}




\subsection{Specimen and material}

As shown in Fig.2, the specimen of the cutting experiment was the aramid honeycomb ACCH-11.83-48 with dimensions of $30 \mathrm{~mm}(\mathrm{~L}) \times 20 \mathrm{~mm}(\mathrm{~W}) \times 12 \mathrm{~mm}(\mathrm{H})$ manufactured by AVIC Composite Corporation, whose paper thickness was $0.05 \mathrm{~mm}$ and resin content was $34.1 \%$. The single wall thickness $t$ was $0.05 \mathrm{~mm}$, both double wall length $a$ and single wall length $b$ were $1.83 \mathrm{~mm}$, corner angle $\varphi$ was $30^{\circ}$. Material properties of the core material, resin and the impregnated honeycomb were given in Table

2. The material properties of the impregnated honeycomb were calculated by Eqs. (1) (8).

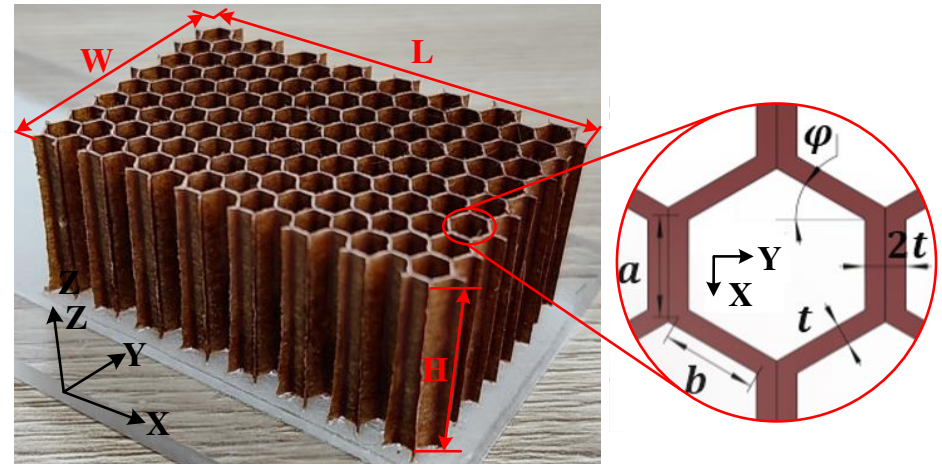

Fig.2 Aramid honeycomb specimen of the cutting experiment.

Table 2 Material properties of the core material $\left[{ }^{18}-\right.$, phenolic resin [Error! Bookmark not defined., $5,{ }^{22}$ ] and impregnated honeycomb.

\begin{tabular}{cccc}
\hline Material properties & Core material & Phenolic resin & Impregnated honeycomb \\
\hline$E_{\mathrm{L}} / \mathrm{MPa}$ & 3000 & 4800 & 3614 \\
$E_{\mathrm{H}} / \mathrm{MPa}$ & 93 & 4800 & 1698 \\
$v$ & 0.193 & 0.389 & 0.26 \\
$S_{\mathrm{LT}} / \mathrm{MPa}$ & 86 & 45.5 & 72 \\
$S_{\mathrm{HT}} / \mathrm{MPa}$ & 38 & 45.5 & 40.6 \\
$S_{\mathrm{LC}}\left(S_{\mathrm{HC}}\right) / \mathrm{MPa}$ & 1.17 & 155 & 53.6 \\
$S_{\mathrm{LS}} / \mathrm{MPa}$ & 1.16 & 49 & 17.5 \\
$S_{\mathrm{HS}} / \mathrm{MPa}$ & 0.67 & 49 & 17.2 \\
$\rho / \mathrm{tmm}$ & $4.8 \times 10^{-10}$ & $1.33 \times 10^{-9}$ & $7.7 \times 10^{-10}$ \\
\hline
\end{tabular}

\subsection{Experimental set-up}

Cutting experiment of the aramid honeycomb was conducted on a three-axis CNC machine 
(maximum spindle speed 12000 r/min). Fig.3(a) shows the experimental set-up. In order to guarantee the clamp effect during the cutting process and improve the stiffness of the honeycomb specimen, it was bonded to an acrylic plate by double sided tape, which is easy to be removed after cutting. Cutting forces in the X-direction and Y-direction plane were measured by a dynamometer 9257B (Kistler, Switzerland, sensitivity $\approx-7.5 \mathrm{pC} / \mathrm{N}$, hysteresis $\leq 0.5 \%$ FSO). Charge amplifier LN5861 (Sino Ceramics, America) and data acquisition USB1902 (ADLINK, China) were used to record data from the dynamometer into a personal computer. The cutting damage size was measured by a digital microscope with super wide depth of field VHX-600E (Keyence, Japan, magnification 20X 5000X). As shown in Fig.3(b), a disc cutter made by 9CrSi with sharp tip was used as the cutting tool, whose diameter was $100.0 \mathrm{~mm}$ and maximum thickness was $1.2 \mathrm{~mm}$. Fig.3(c) shows the cutting process: (I) at the initial state, there is no contact between the cutter and the workpiece; (II) at the cut-in state, the contact width between the cutter arc and workpiece equals to the width of the workpiece; (III) after the cut-out state, the contact width will be less than the width of the workpiece; (IV) at the final state, the workpiece is completely cut through. During the cutting experiment, spindle speed was $n_{\mathrm{C}}=5000 \mathrm{r} / \mathrm{min}$, feed speed was $V_{\mathrm{X}}=25 \mathrm{~mm} / \mathrm{min}$, cutting depth was $h=6$ $\mathrm{mm}$. The cutting experiment had been replicated for three times with same conditions.
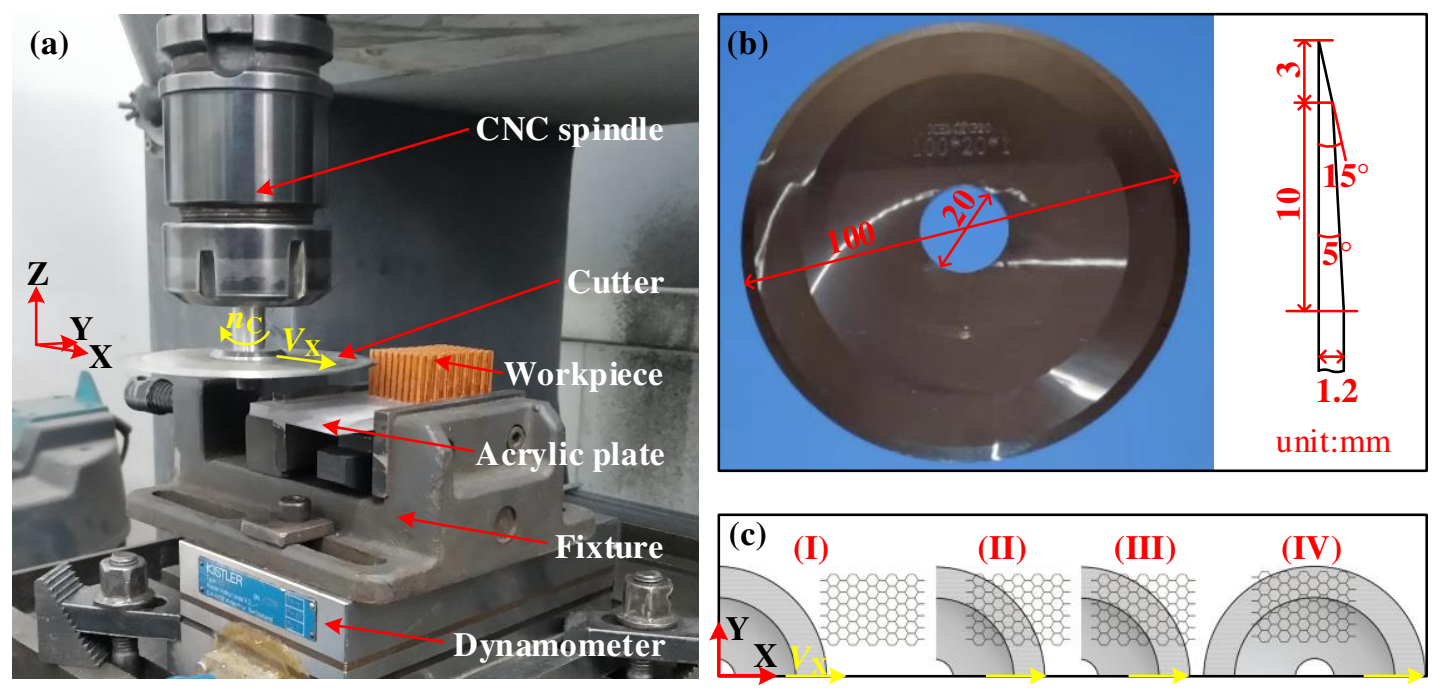

Fig.3 Experimental set-up and cutting process: (a) experimental set-up; (b) disc cutter; (c) cutting process of the honeycomb. 


\section{Results and Discussion}

\subsection{Validation results}

The charge amplifier converted the measurement signals into electrical voltages, which were exactly proportional to the force acting. Then raw force signals 'Fx-raw signal' (along the cutting direction) and 'Fy-raw signal' (transverse to the cutting direction) were obtained. In order to reduce the interference of high frequency signal, the raw signals from the experiments were smoothed by Savitzky-Golay method with second order polynomial and 150 points of windows in Origin software. As a result, the smoothed cutting force-time curves 'Fx-EXP' and 'Fy-EXP' in Fig.4 were obtained. Then they were compared with the predicted data from the FEM.

As can be seen in Fig.4, the predicted 'cutting force-time' responses 'Fx-FEM' and 'Fy-FEM' were close to the results from the experiments. The average cutting forces of the experiment (smoothed curves) between the cut-in state (time $9.4 \mathrm{~s}$ ) and the cut-out state (time $16.88 \mathrm{~s}$ ) are $\mathrm{Fx}=2.09 \mathrm{~N}$ and Fy=0.85 N, while that of the FEM are $F x=2.85 \mathrm{~N}$ and $\mathrm{Fy}=0.24 \mathrm{~N}$. Maximum cutting force $\mathrm{Fx}$ of the experiment (smoothed curve) is $4.62 \mathrm{~N}$, while that of the FEM is $3.08 \mathrm{~N}$. Maximum cutting force Fy of the experiment (smoothed curve) is $1.51 \mathrm{~N}$, while that of the FEM is $0.85 \mathrm{~N}$. Considering the simulation error caused by the mass scaling method and the material properties error between the FEM and the experiment specimen, the differences between the FEM results and experimental results were in an acceptable range.

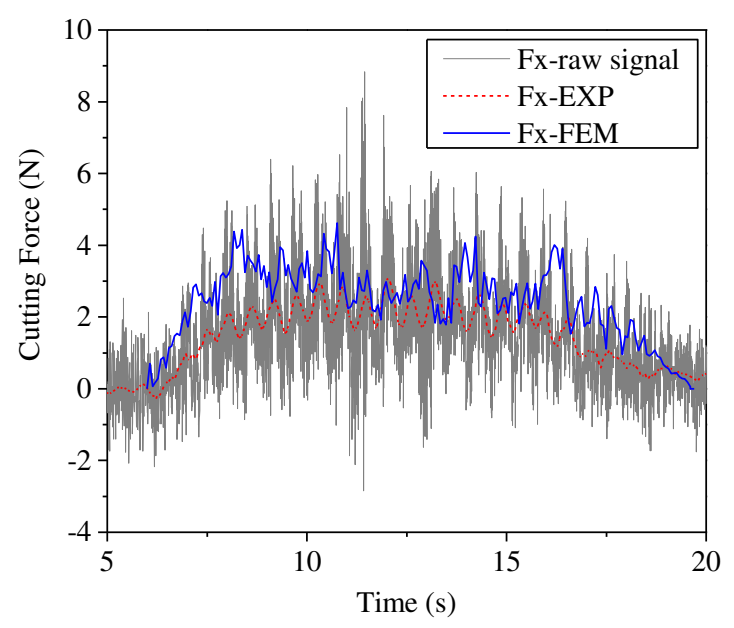

(a)

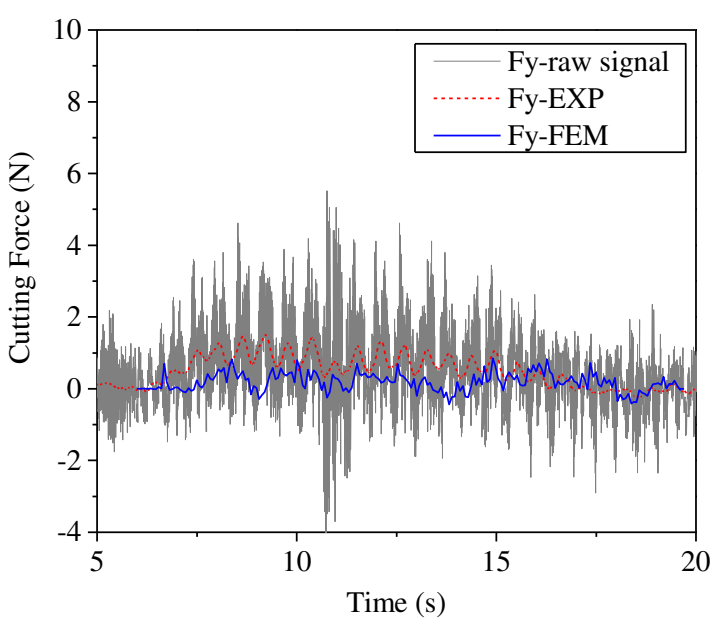

(b) 
Fig.4 Comparison of cutting forces from experiments and finite element model: (a) along the cutting direction; (b) transverse to the cutting direction.

Damages of the specimen from the experiment and the FEM were shown in Fig.5. It was found that major damages in the process of cutting aramid honeycomb conclude tear, uncut fiber and burr. Cutting force acting on the low stiffness cell wall of the honeycomb in the cutting direction makes the cell wall bent, which will relieve the cutting force, and strong plasticity of the aramid fiber makes it hard to break. As a result, there will be uncut fiber and burr damages. Tear damage was formed due to weak support on the cell wall and bad bonding effect between fibers and resin. All abovementioned damages from the FEM were in good agreement with predicted damages from the experiment, therefore, the proposed finite element method was effective to investigate the cutting process for the aramid honeycomb.
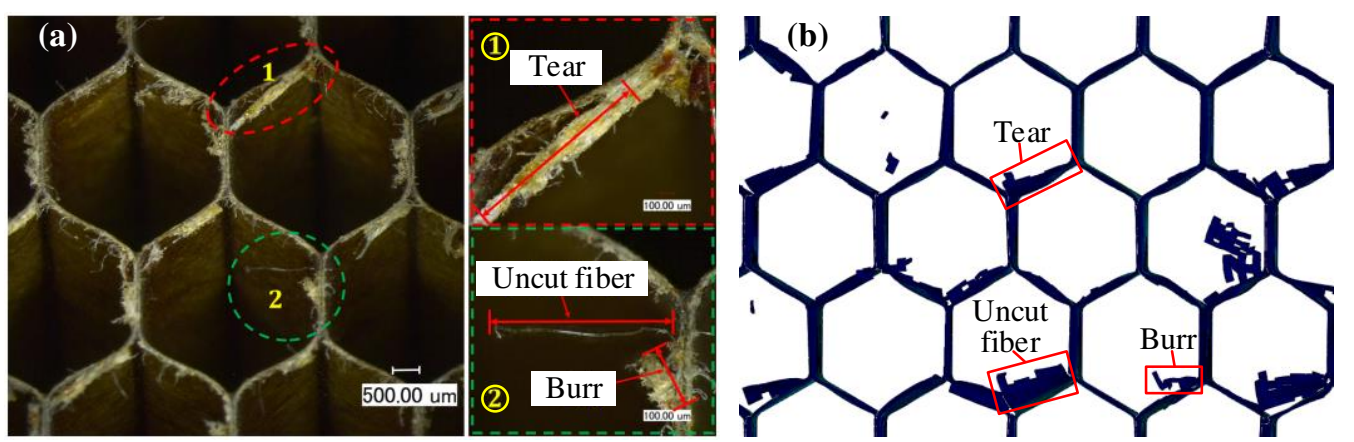

Fig.5 Comparison of damages from the (a) experiments and (b) FEM.

\subsection{Cutting mechanism}

Using the validated finite element method, the cutting mechanism of the Aramid honeycomb can be revealed visually. The cutting process with sharp disc cutter predicted by the FEM was shown in Fig.6. After the initial state, the cutter starts to contact cell wall of the honeycomb. The cells near the cutter start to deform under the thrust force of the cutter, and it will be cut off when the fiber tensile failure criterion or fiber compressive failure criterion was met. When it comes to the cut-in state (as specified in Fig.3(c)), sliding-mode cracking (Mode II fracture) can be seen, which is related with the cutter tip geometry (discuss later). And tear damage occurs as marked by red triangles. At the cut-out state, the workpiece was cut off in opening-mode cracking (Mode I fracture) and sliding-mode cracking (Mode II fracture) modes. At the 
final state, the workpiece was completely cut through in the Mode I \& Mode II mixed fracture mode with significant tensile fracture of the cell wall due to weak support.

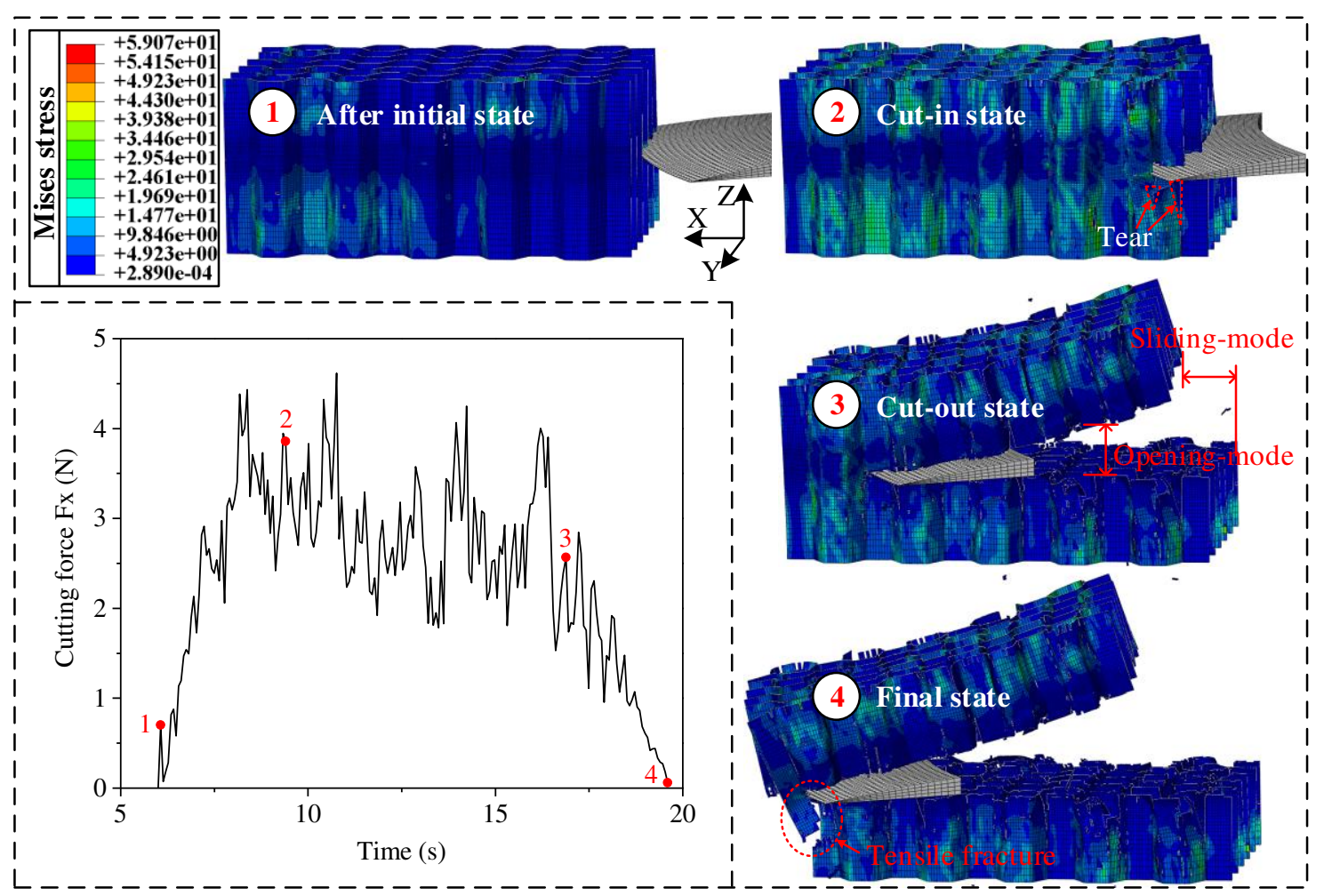

Fig.6 Predicted cutting process with sharp disc cutter by FEM.

\subsection{Effect of the cutter tip geometry}

The cutting quality of the aramid honeycomb is strongly related to the cutter tip geometry. Two types of disc cutters were compared, sharp disc cutter and blunt disc cutter, as shown in Fig.7. Comparing the free-body diagrams of the honeycomb cutting with two different cutters, it is reasonable to predict that the honeycomb cut by the sharp disc cutter will fracture in the mixed-mode cracking mode, while the honeycomb cut by the blunt disc cutter will fracture in the sliding-mode cracking dominant mode. Meanwhile, deformation along the $\mathrm{X}$-axis of the honeycomb cut by the blunt disc cutter will be greater than that cut by the sharp disc cutter due to the fact that thrust force of the blunt tool along the cutting direction is higher than that of the sharp tool. 


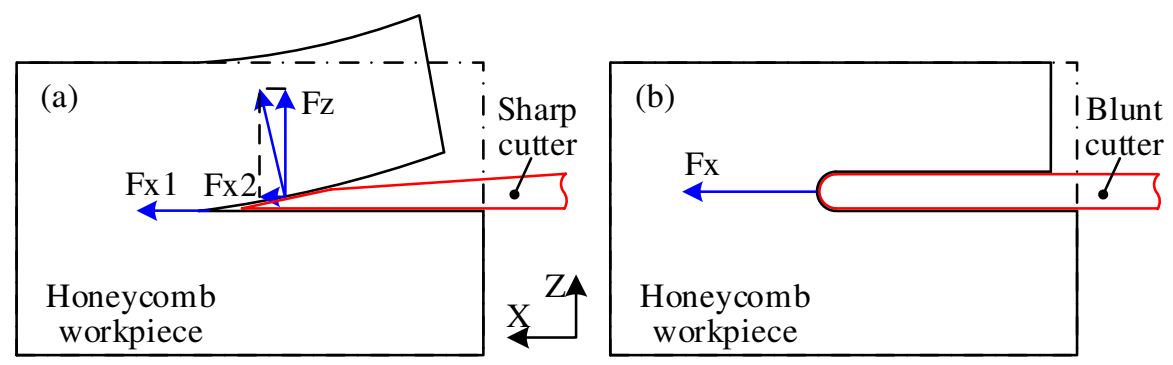

Fig.7 Free-body diagrams of honeycomb cutting with different cutters: (a) sharp cutter; (b) blunt cutter.

Predicted cutting deformation at the cut-out state and predicted cutting force Fx by the FEM with different cutter tip geometries (sharp disc cutter and blunt disc cutter) were compared in Fig.8. The honeycomb cut by the sharp disc cutter deforms along the $\mathrm{X}$-axis and Z-axis obviously, while that cut by the blunt disc cutter mainly deforms along the X-axis. It means that the honeycomb fractures in the mixedmode for the former, while it fractures in the sliding-mode cracking dominant mode for the latter. And deformation along the $\mathrm{X}$-axis for honeycomb cut by the blunt disc cutter is much greater than that cut by the sharp disc cutter, which has good agreement with the analytical results in Fig.7. Meanwhile, the honeycomb cut by the blunt disc cutter has been fractured before the cutter is completely cut out due to big thrust force of the blunt cutter tip, which leads to sudden drop of the cutting force at the cut-out state (time=16 s) as shown in Fig.8(b). Therefore, it can be concluded that sharp tip cutter for aramid honeycomb cutting is advantageous to obtain good cutting quality and lower cutting force.

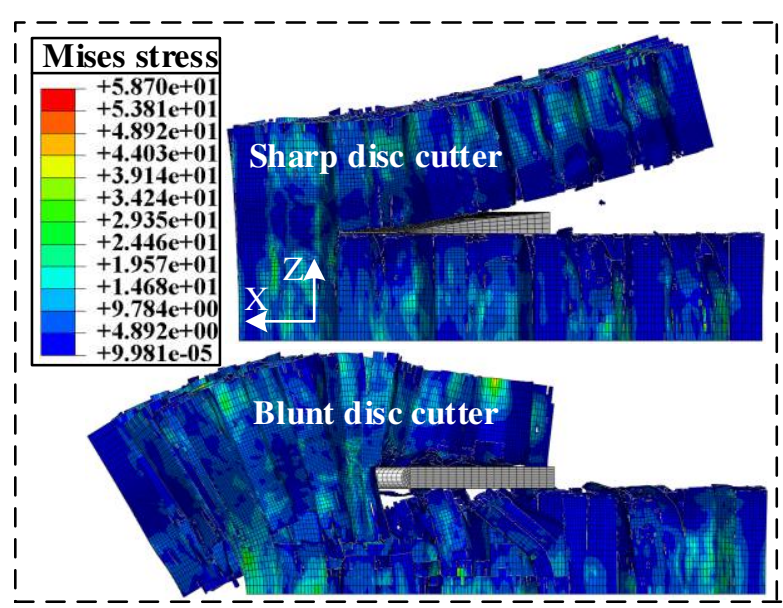

(a)

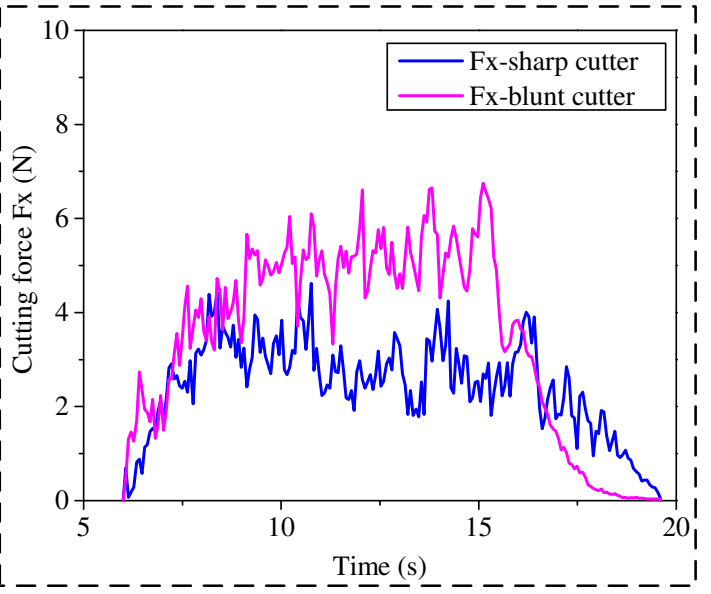

(b)

Fig. 8 Predicted cutting deformation and predicted cutting force with different cutter tip geometries: (a) cutting deformation; (b) cutting force. 


\subsection{Effect of the workpiece boundary conditions}

In order to study the effect of the workpiece boundary conditions on the cutting mechanism, two different boundary conditions $\mathrm{BC} 1$ and $\mathrm{BC} 2$ were studied. As shown in Fig.9, the boundary condition BC1 represents that top of the honeycomb is free, while the $\mathrm{BC} 2$ represents that top of the honeycomb is bonded to an acrylic plate. It should be noted that the boundary condition on the top of the honeycomb was represented by rigid body constraint, in which the topmost nodes were tied to a reference point as a rigid body. The bottom of the honeycomb is fixed in the FEM for both boundary conditions BC1 and BC2.

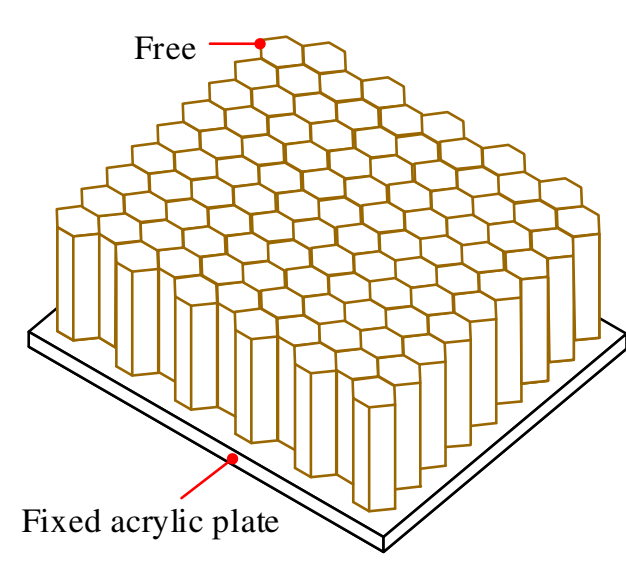

(a)

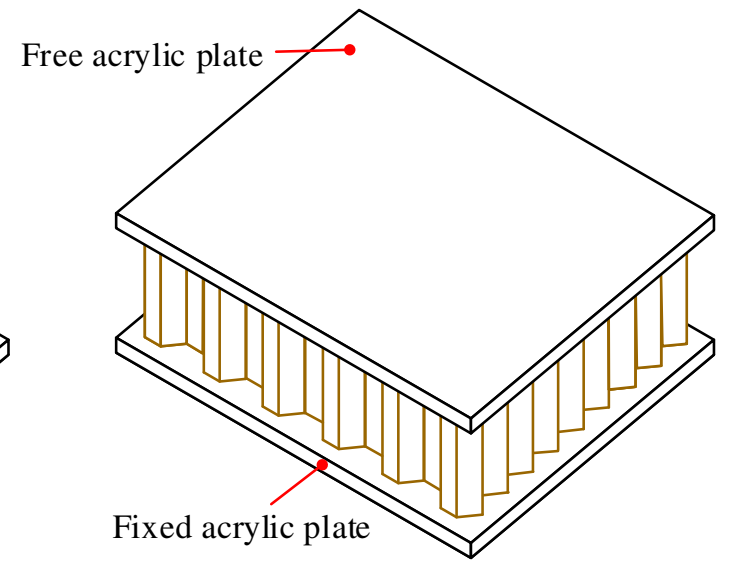

(b)

Fig.9 Illustration of boundary conditions for the honeycomb: (a) BC1; (b) BC2.

The contours of Mises stress for the aramid honeycomb cutting with boundary conditions BC1 and $\mathrm{BC} 2$ at the same cutting length along the X-axis are shown in Fig.10. It can be seen that deformation of the top part of the honeycomb at the $\mathrm{Z}$-axis for the $\mathrm{BC} 1$ configuration is obviously greater than that for the $\mathrm{BC} 2$ configuration because the rigid body constraint limits the bending deformation on the top of the honeycomb. As a result, sliding-mode cracking (Mode II fracture) dominates the honeycomb cutting process for the $\mathrm{BC} 2$ configuration, while opening-mode cracking (Mode I fracture) is less important, which results in that cutting force $\mathrm{Fx}$ of the $\mathrm{BC} 2$ configuration is bigger than that of the $\mathrm{BC} 1$ configuration in Fig.10(b). In the enlarged view of Fig.10(a), cutting damages of the BC2 configuration are less serious than that of the $\mathrm{BC} 1$ configuration due to the rigid body constraint on the top of the honeycomb makes the workpiece stiffer. It can be concluded that bonding both top and bottom of the honeycomb to two stiffer 
parts individually will be beneficial to obtain good cutting quality for aramid honeycomb cutting although it increases the cutting force.

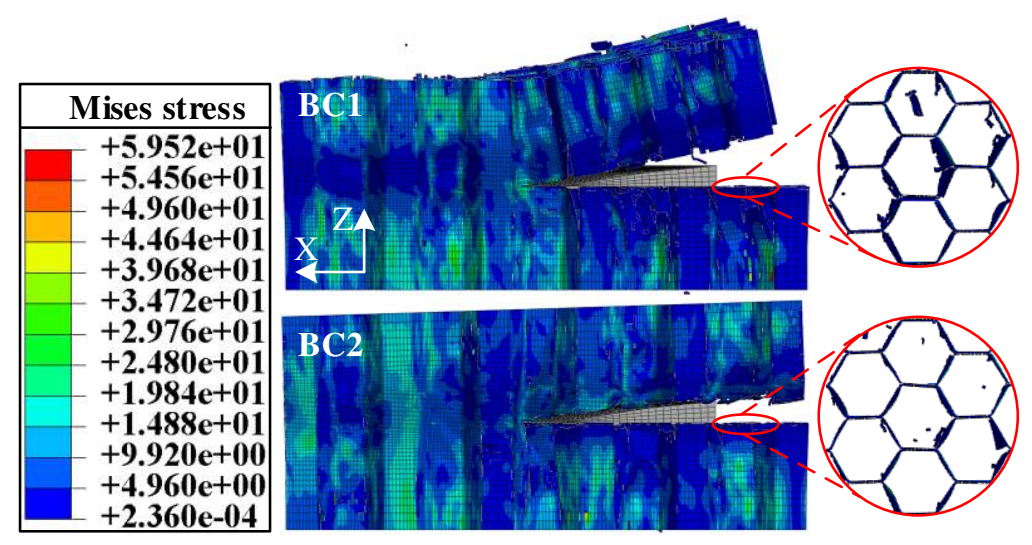

(a)

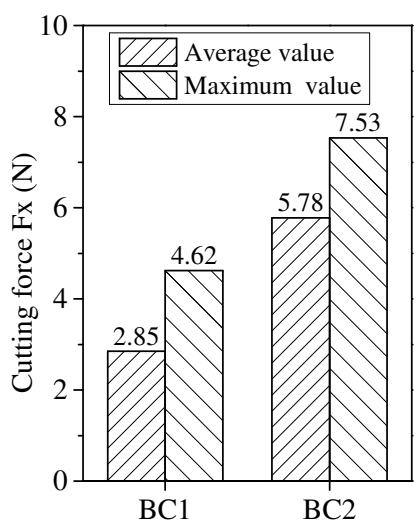

(b)

Fig.10 Predicted cutting deformation and predicted cutting force under different workpiece boundary conditions: (a) cutting deformation; (b) cutting force.

\section{Conclusion}

In this paper, a finite element modeling method based on 3D Hashin criteria was proposed to investigate the aramid honeycomb cutting process, which can effectively predict the cutting damages and reveal the cutting mechanism. The proposed method solved the problem of efficient honeycomb cutting modeling by imitating the real manufacturing process, and it solved the problem of honeycomb material assignment in the finite element model by developing a material calculating method considering material properties of the core material and the resin. A validation experiment was conducted for ACCH-1-1.83-48 aramid honeycomb specimen. The comparison results of cutting force response and cutting damages between the finite element model and the experiment validated that the proposed method was effective to investigate the cutting process for the aramid honeycomb. Major conclusions are as follows:

(1) cutting process of the aramid honeycomb can be divided into 3 stages with 4 characteristic states: initial state, cut-in state, cut-out state and final state; the aramid honeycomb was cut off in the Mode I \& Mode II mixed fracture mode;

(2) cutting force acting on the low stiffness cell wall of the honeycomb in the cutting direction makes 
the cell wall bent, which will relieve the cutting force, and strong plasticity of the aramid fiber makes it hard to break. As a result, there will be uncut fiber and burr damages;

(3) using sharp tip cutter is advantageous to obtain good cutting quality with less damages and lower cutting force;

(4) bonding both top and bottom of the honeycomb to two stiffer parts individually will be beneficial to obtain good cutting quality for aramid honeycomb cutting although it increases the cutting force.

\section{Availability of Data and Materials}

The datasets used and/or analysed during the current study are available from the corresponding author on reasonable request.

\section{Competing Interests}

The authors declare that they have no competing interests.

\section{Funding}

This work was supported by the China Postdoctoral Science Foundation [Grant No. 2020M680937 \& No. 2020M670734] (Data collection), National Natural Science Foundation of China [Grant No. 51875079] (Equipment support), National Key Research and Development Project [Grant No. 2020YFB2009805] (Data analysis), and LiaoNing Revitalization Talents Program [Grant No. XLYC1907196] (Writing support).

\section{Authors' Contributions}

YY wrote the article and analysed the data. BY proposed the idea of experiments. QX assisted to conduct the experiments. WJ contributed to review the article.

\section{Acknowledgements}

The authors would like to acknowledge the abovementioned financial support.

\section{References}


[1] Farooq, U., Ahmad, M.S., Rakha, S.A., Ali, N., Khurram, A.A., \& Subhani, T. (2017). Interfacial mechanical performance of composite honeycomb sandwich panels for aerospace applications. Arabian Journal for Science and Engineering, 42, 1775-1782.

[2] Thomsen, M., Huang, X., \& Fernandez-Pello, C. (2019). Concurrent flame spread over externally heated Nomex under mixed convection flow. Proceedings of the Combustion Institute, 37(3), 38013808.

[3] Zhai, J., Liu, Y., Geng, X., Zheng, W., Zhao, Z., Cui, C., \& Li, M. (2019). Energy absorption of prefolded honeycomb under in-plane dynamic loading. Thin-Walled Structures, 145, 106356.

[4] DuPont. (2016). Typical mechanical properties of Nomex 410. http://www.dupont.com.

[5] Roy, R., Park, S., Kweon, J., \& Choi, J. (2014). Characterization of Nomex honeycomb core constituent material mechanical properties. Composite Structures, 117, 255-266.

1 Z Zhou, Y., Liu, A., Xu, Y., Guo, Y., Yi, X., \& Jia, Y. (2021). Frequency-dependent orthotropic damping properties of Nomex honeycomb composites. Thin-Walled Structures, 160, 107372.

2 ] Birman, V., \& Kardomateas, G.A. (2018). Review of current trends in research and applications of sandwich structures. Composite Part B: Engineering, 142, 221-240.

$3 \square$ Gill, D.D., Yip-Hoi, D.M., Meaker, M., Boni, T., Eggeman, E.L., Brennan, A.M., \& Anderson, A. (2017). Studying the mechanisms of high rates of tool wear in the machining of aramid honeycomb composites. ASME, MSEC2017-2694, V002T03A002.

4 ] Icardi, U., \& Sola, F. (2015). Indentation of sandwiches using a plate model with variable kinematics and fixed degrees of freedom. Thin-Walled Structures, 86, 24-34.

5 ] Farooq, U., Ahmad, M.S., Rakha, S.A., Ali, N., Khurram, A.A., \& Subhani, T. (2017). Interfacial mechanical performance of composite honeycomb sandwich panels for aerospace applications. Arabian Journal for Science and Engineering, 42, 1775-1782.

6 Thomsen, M., Huang, X., \& Fernandez-Pello, C. (2019). Concurrent flame spread over externally 
heated Nomex under mixed convection flow. Proceedings of the Combustion Institute, 37(3), 3801-3808.

7 Zhai, J., Liu, Y., Geng, X., Zheng, W., Zhao, Z., Cui, C., \& Li, M. (2019). Energy absorption of pre-folded honeycomb under in-plane dynamic loading. Thin-Walled Structures, 145, 106356.

8 Y Yang, C., Xu, P., Yao, S., Xie, S., Li, Q., \& Peng, Y. (2018). Optimization of honeycomb strength assignment for a composite energy-absorbing structure. Thin-Walled Structures, 127, 741-755.

9 Garakoç, A., \& Freund, J. (2012). Experimental studies on mechanical properties of cellular structures using Nomex® honeycomb cores. Composite Structures, 94(6), 2017-2024.

10 Zhou, Y., Wang, Q., Guo, Y., Xu, Y., Yi, X., \& Jia, Y. (2018). Effect of phenolic resin thickness on frequency-dependent dynamic mechanical properties of Nomex honeycomb cores. Composites Part B: Engineering, 154, 285-291.

11 ] Alp, K., \& Jouni, F. (2012). Experimental studies on mechanical properties of cellular structures using Nomex® honeycomb cores. Composite Structures, 94(6), 2017-2024.

12 Kang, D., \& Zou, P. (2019). Study on ultrasonic vibration-assisted cutting of Nomex honeycomb cores. The International Journal of Advanced Manufacturing Technology, 104, 979-992.

13 Seemann, R., \& Krause, D. (2017). Numerical modelling of Nomex honeycomb sandwich cores at meso-scale level. Composite Structures, 159, 702-718.

14 Wang, R., \& Wang, J. (2018). Modeling of honeycombs with laminated composite cell walls. Composite Structures, 184, 191-197.

15 ] Gibson, L.J., \& Ashby, M. F. (1997). Cellular solids: structure and properties. Cambridge: Cambridge University Press.

16 Wang, H., Wang, Y., Yao, Y., Hu, J., \& Yang, J. (2013). The relationship between aramid paper honeycomb mechanical properties and paper performance (in Chinese). Journal of Functional Materials, 44(03),

https://kns.cnki.net/kcms/detail/detail.aspx?dbcode=CJFD\&dbname=CJFD2013\&filename=GNCL2013 03012\&v=a\%25mmd2F4wTvxyZqH9Vnrf\%25mmd2FggIzp9ZeukYMc1gMrV1ZFK4v0VjK8XQFVW 
caRvSAUQDDJpO.

17 Jaafar, M., Atlati, S., Makich, H., Nouari, M., Moufki, A., \& Julliere, B. (2017). A 3D FE modeling of machining process of Nomex ${ }^{\circledR}$ honeycomb core: influence of the cell structure behaviour and specific tool geometry. Procedia CIRP, 58, 505-510.

18 AVIC Composite Co. (2020). Mechanical properties of aviation-class aramid paper honeycomb core at room temperature. http://www.aviccht.com.cn.

19 ] DuPont. (2016). Typical mechanical properties of Nomex 410. http://www.dupont.com.

20 Roy, R., Park, S., Kweon, J., \& Choi, J. (2014). Characterization of Nomex honeycomb core constituent material mechanical properties. Composite Structures, 117, 255-266.

21 Feng, H., Liu, L., \& Zhao, Q. (2017). Experimental and numerical investigation of the effect of entrapped air on the mechanical response of Nomex honeycomb under flatwise compression. Composite Structures, 182, 617-627.

22 ] Xie, S.C., Wang, H., Yang, C.X., Zhou, H., \& Feng, H. (2020). Mechanical properties of combined structures of stacked multilayer Nomex ${ }^{\circledR}$ honeycombs. Thin-Walled Structures, 151, 106729. 
Figures

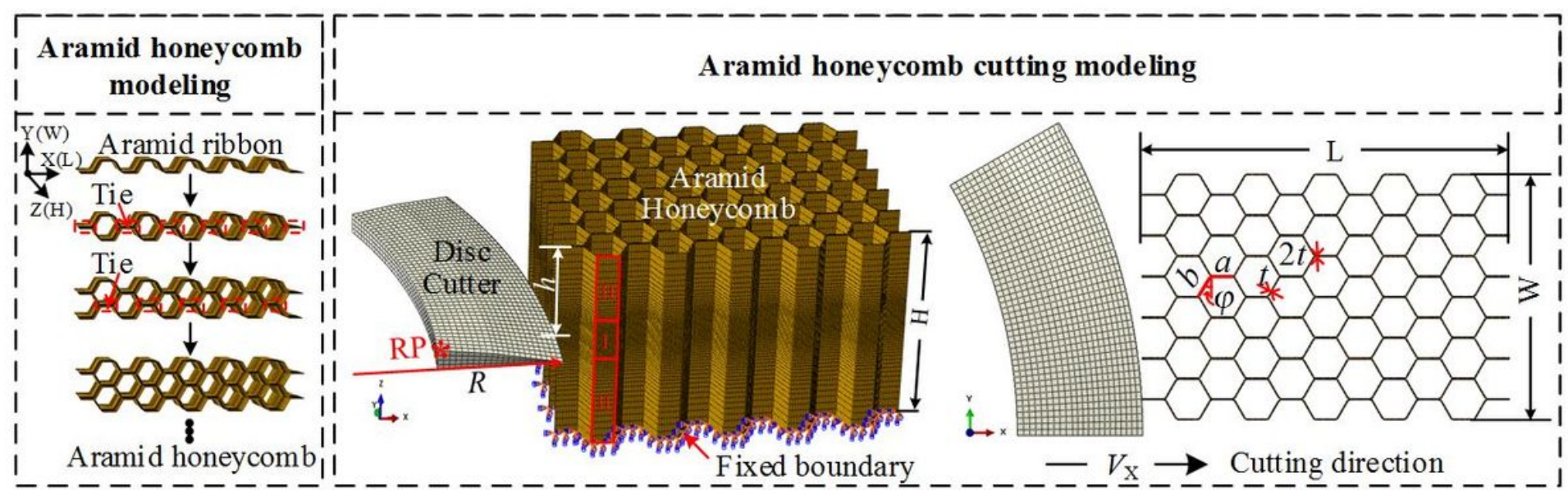

Figure 1

Finite element modeling of the aramid honeycomb cutting process.

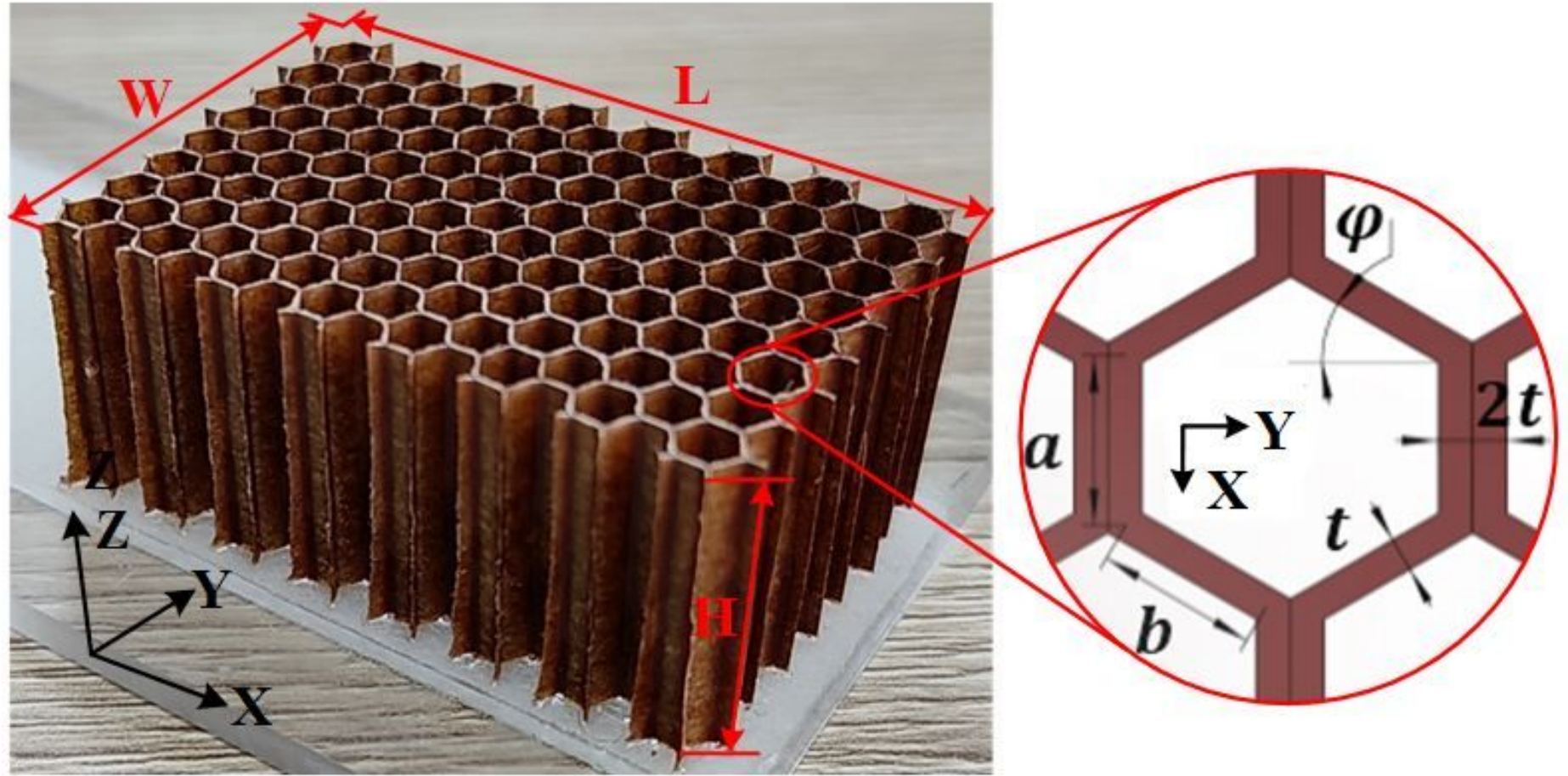

Figure 2

Aramid honeycomb specimen of the cutting experiment. 

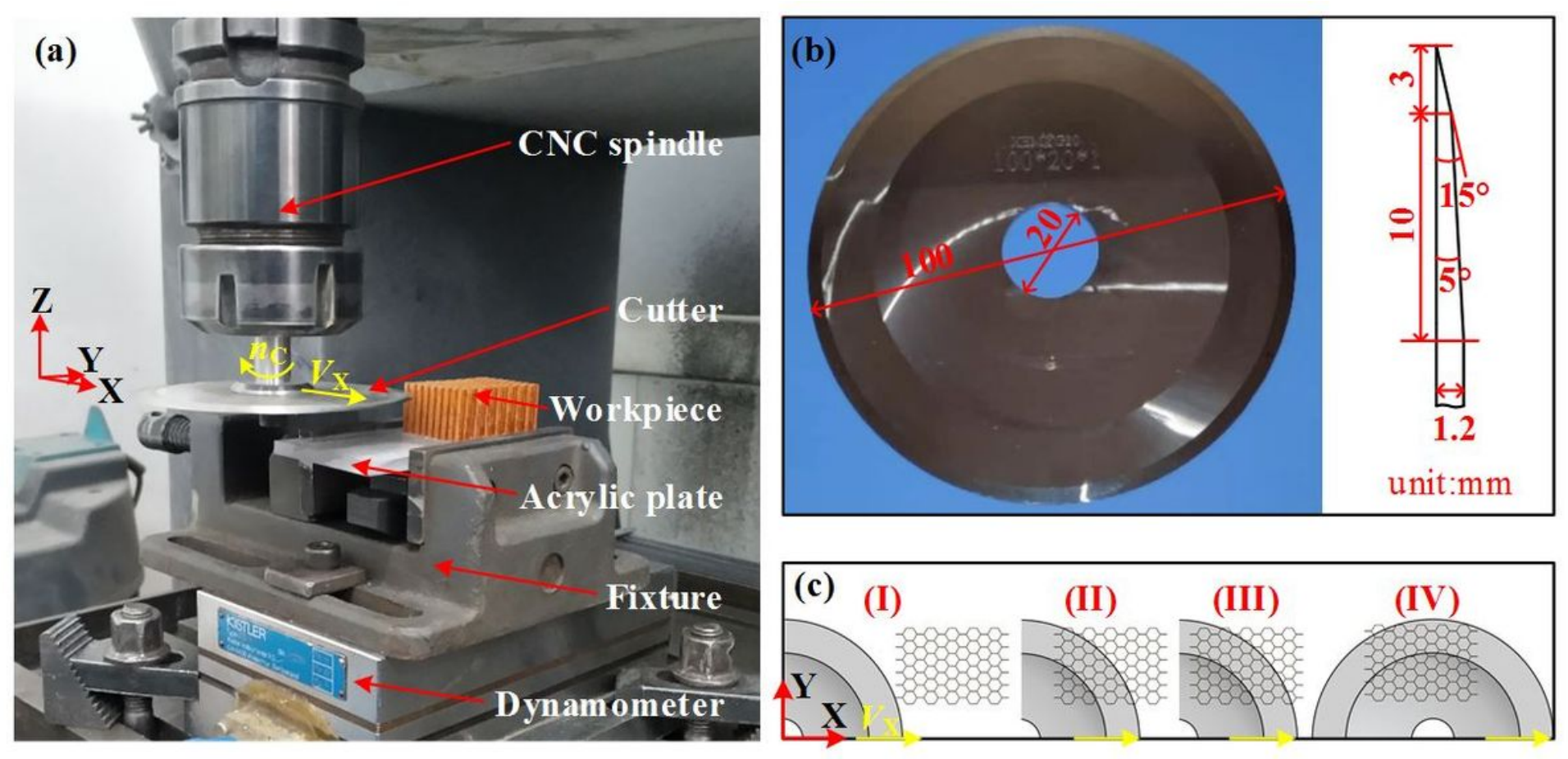

\section{Figure 3}

Experimental set-up and cutting process: (a) experimental set-up; (b) disc cutter; (c) cutting process of the honeycomb.

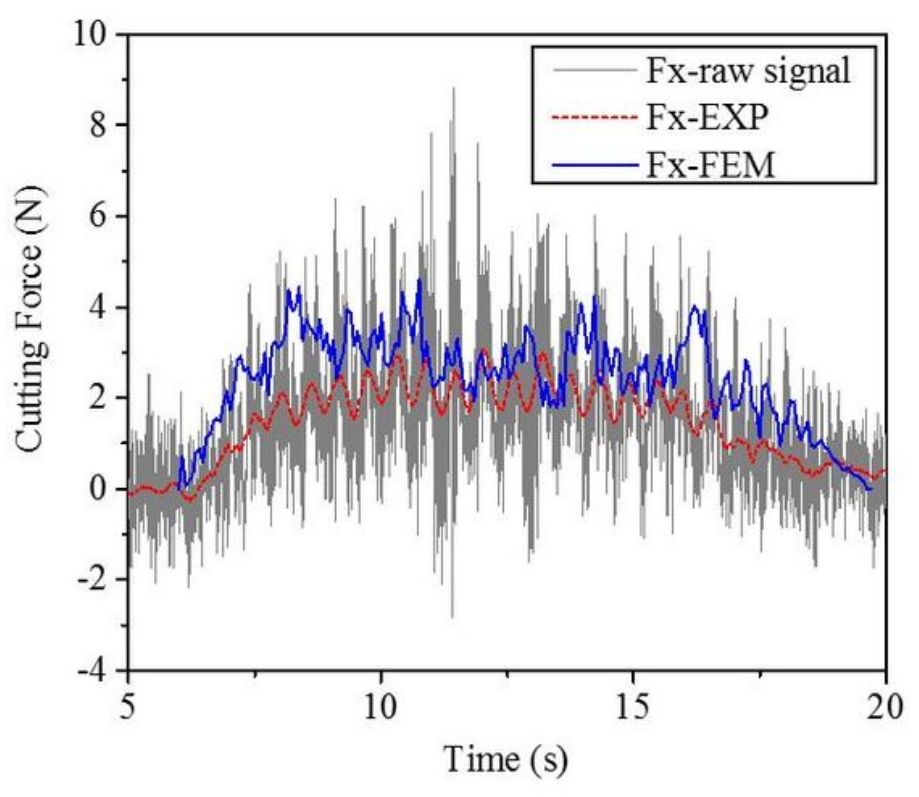

(a)

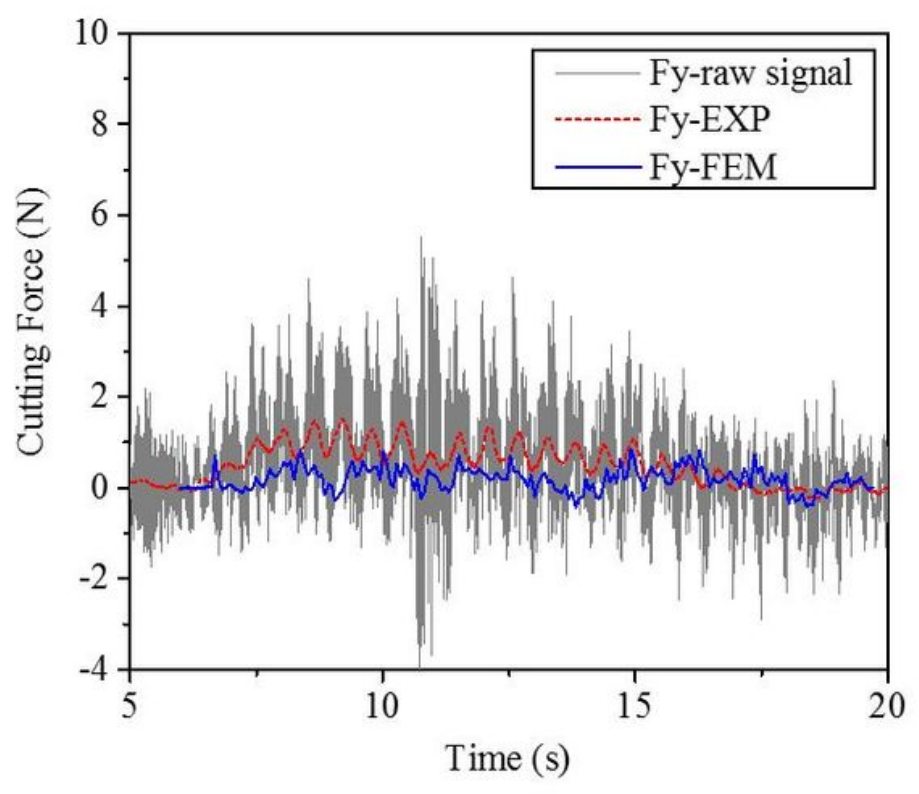

(b)

\section{Figure 4}

Comparison of cutting forces from experiments and finite element model: (a) along the cutting direction; (b) transverse to the cutting direction. 

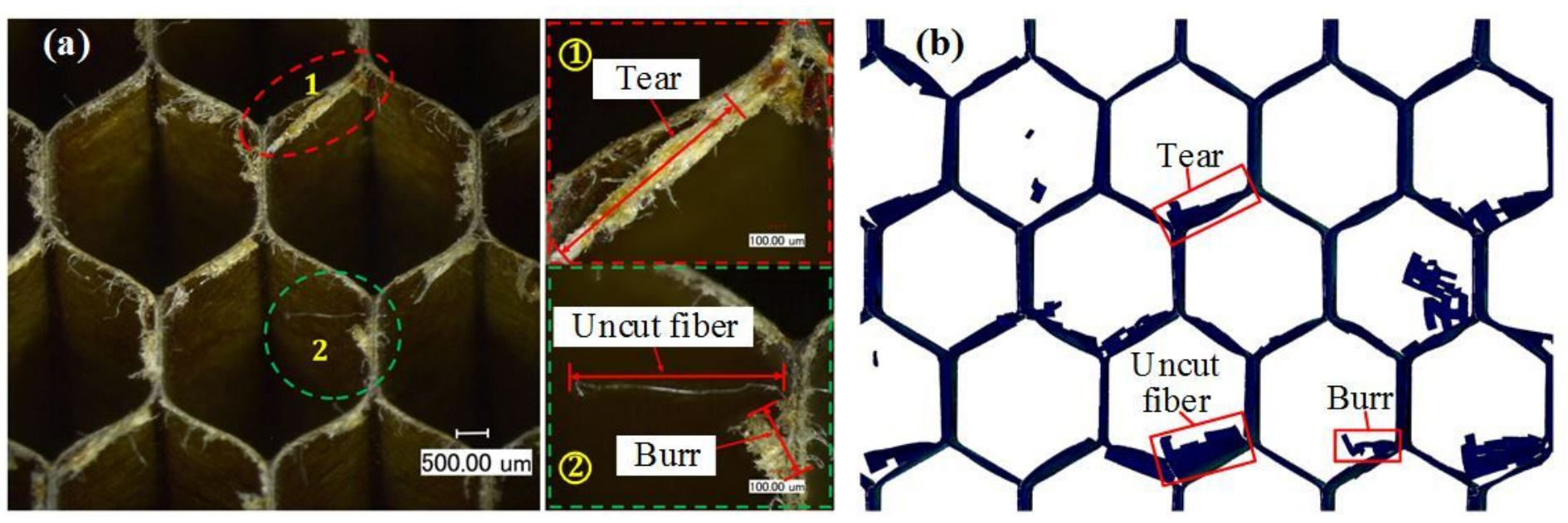

Figure 5

Comparison of damages from the (a) experiments and (b) FEM.

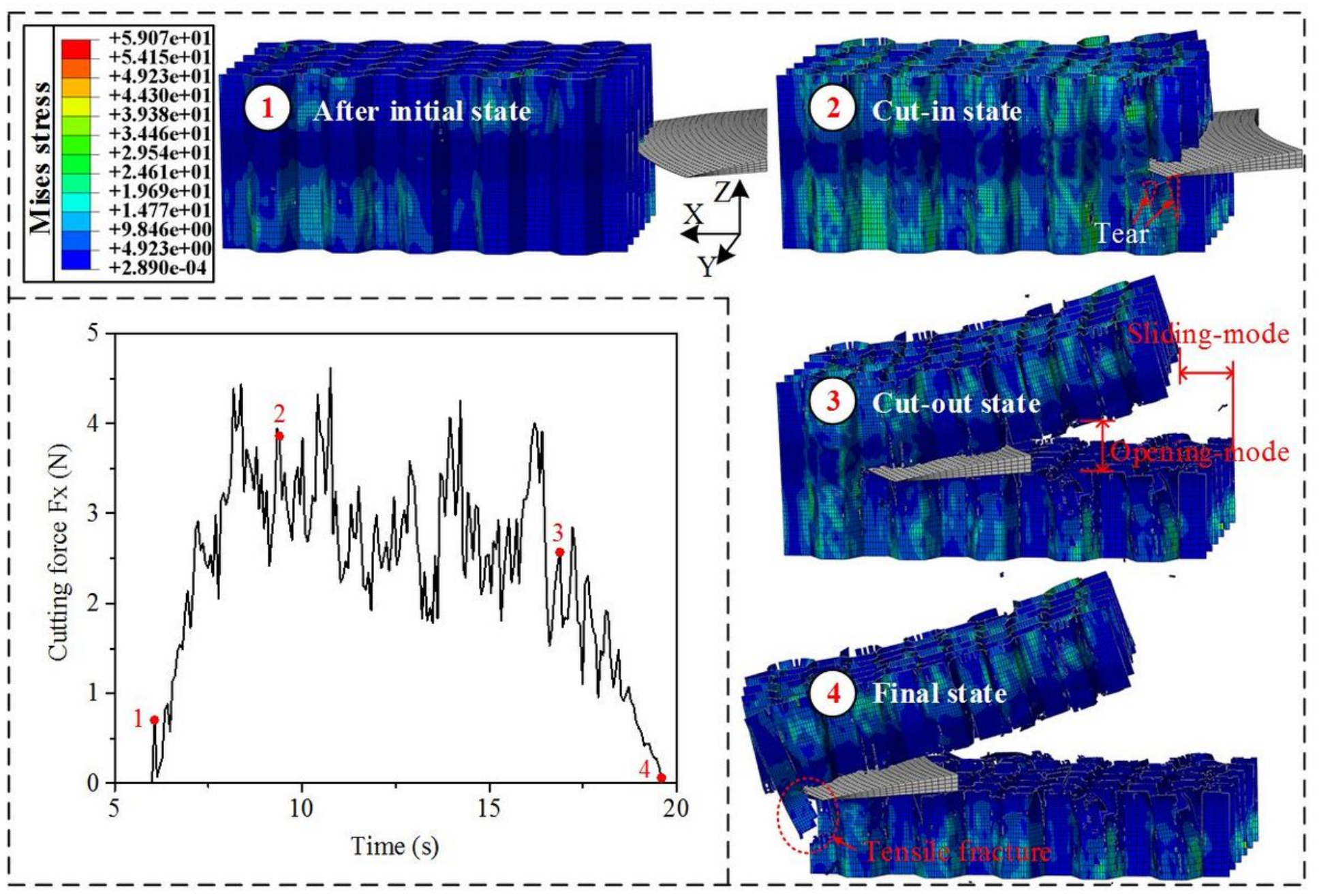

Figure 6

Predicted cutting process with sharp disc cutter by FEM. 


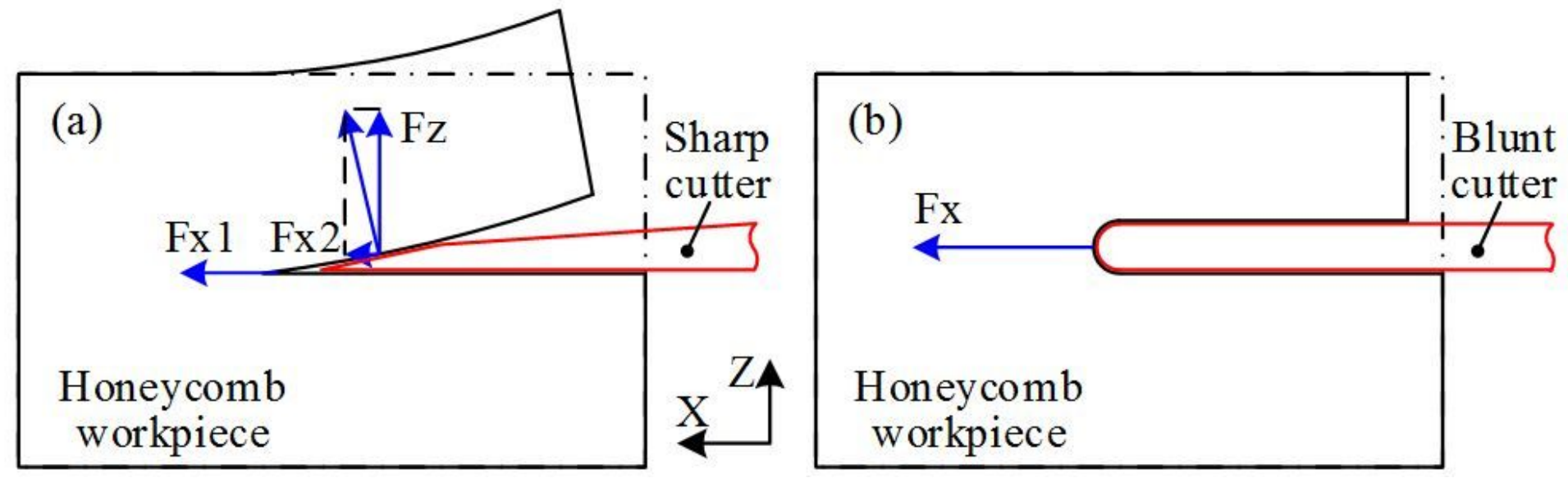

Figure 7

Free-body diagrams of honeycomb cutting with different cutters: (a) sharp cutter; (b) blunt cutter.

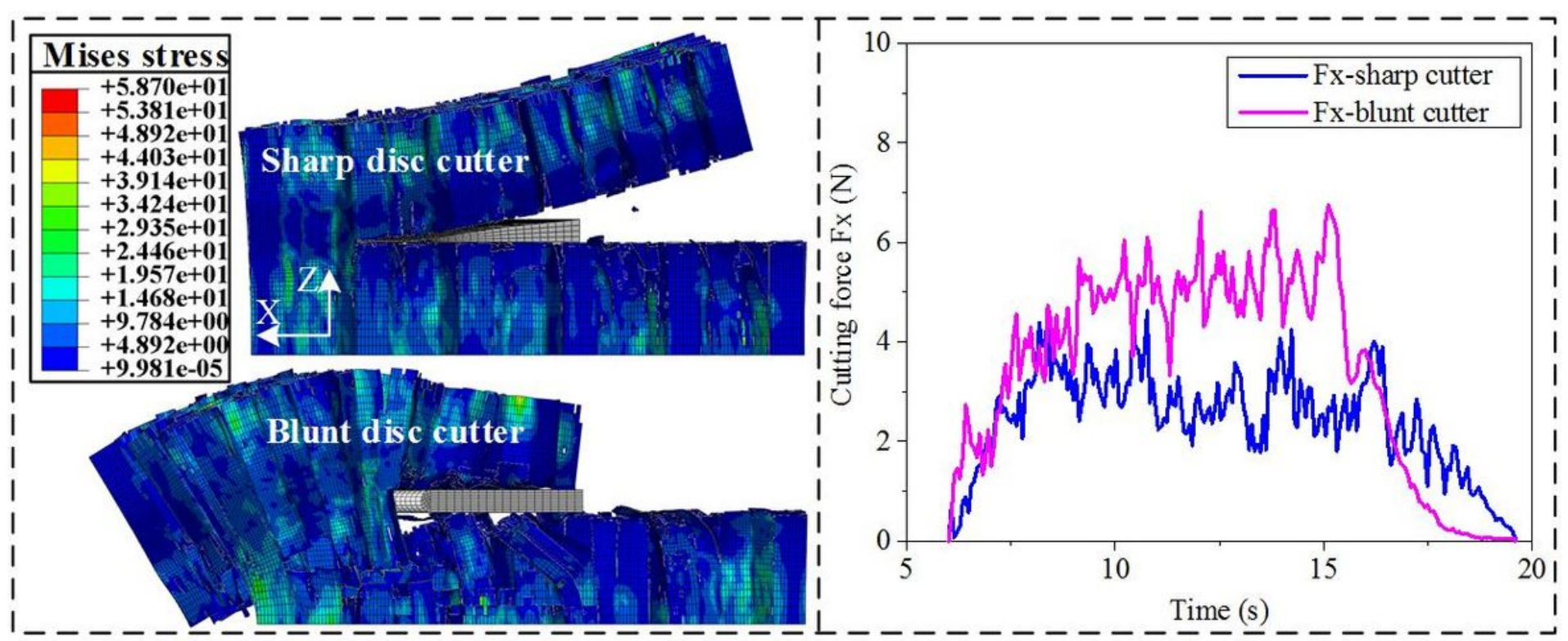

(a)

(b)

Figure 8

Predicted cutting deformation and predicted cutting force with different cutter tip geometries: (a) cutting deformation; (b) cutting force. 


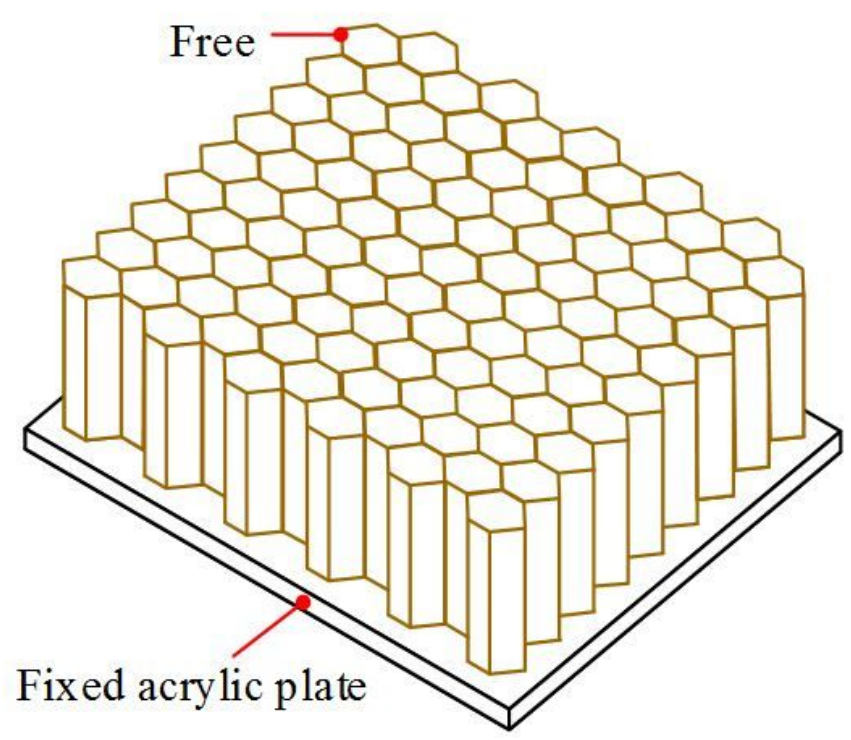

(a)

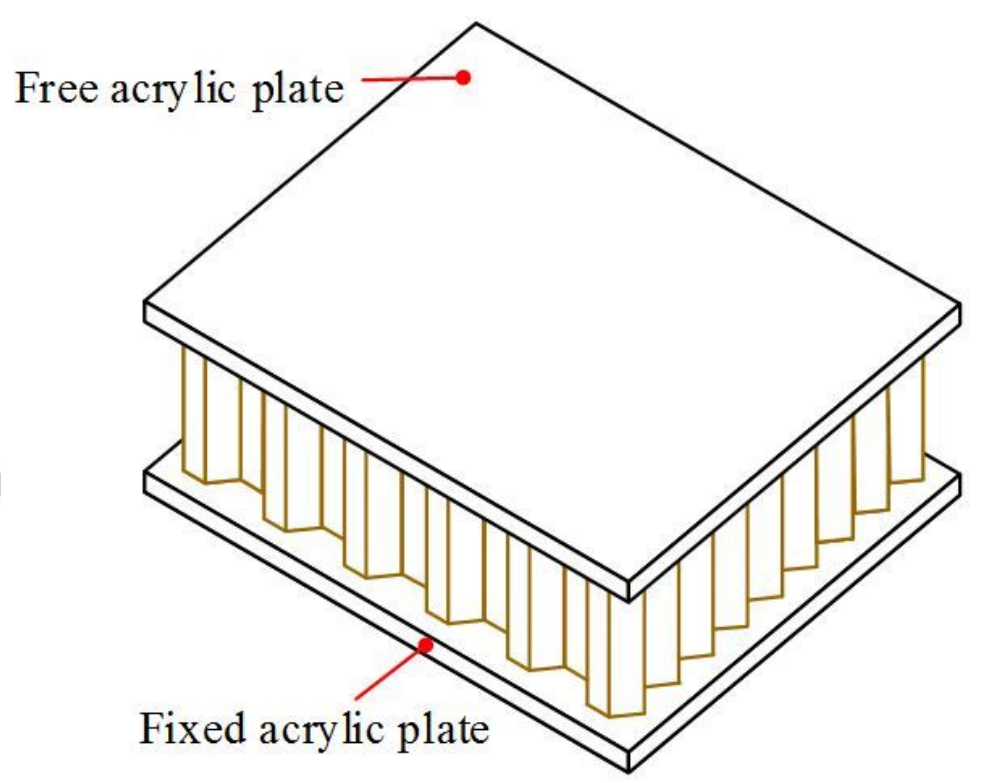

(b)

\section{Figure 9}

Illustration of boundary conditions for the honeycomb: (a) BC1; (b) BC2.

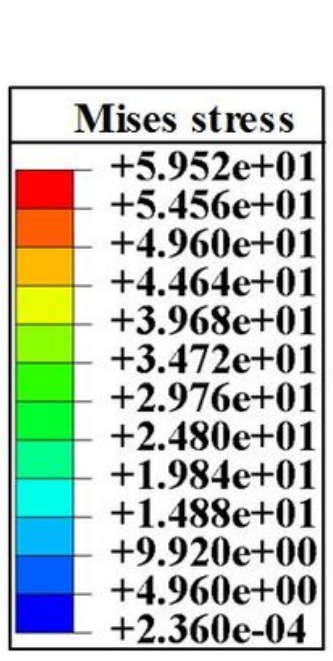

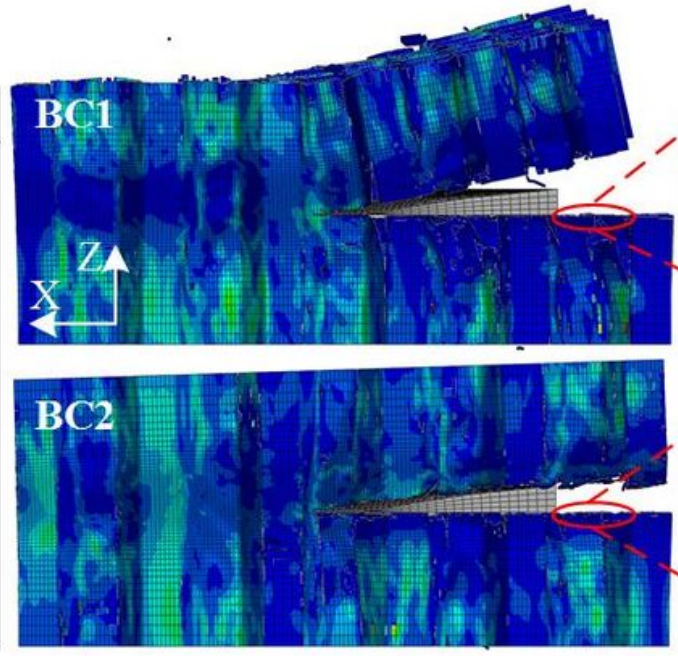

(a)
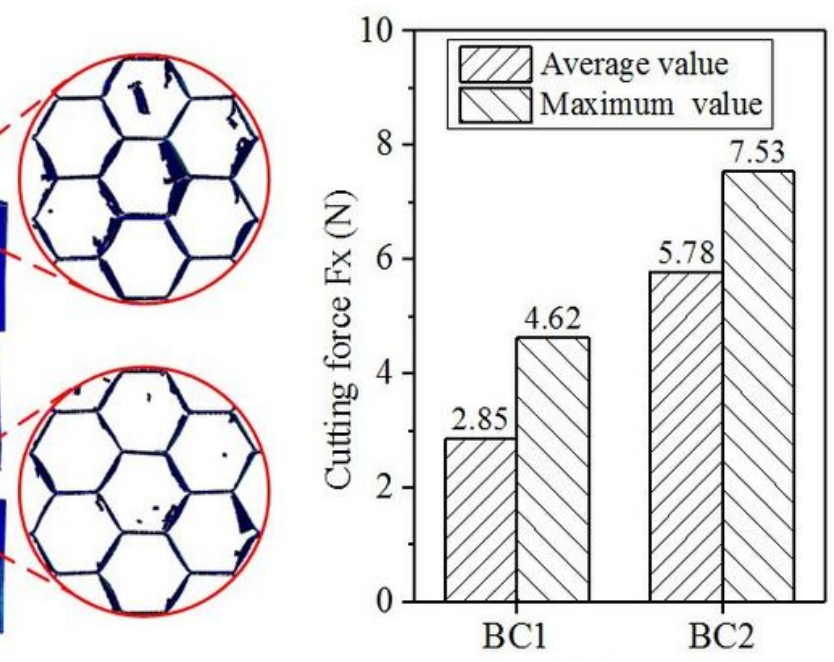

(b)

Figure 10

Predicted cutting deformation and predicted cutting force under different workpiece boundary conditions:

(a) cutting deformation; (b) cutting force. 